\title{
Randomized phase 2 study of adjunctive cenobamate in patients with uncontrolled focal seizures
}

Steve S. Chung, MD, Jacqueline A. French, MD, Jacek Kowalski, MD, Gregory L. Krauss, MD, Sang Kun Lee, MD, Maciej Maciejowski, MD, PhD, William E. Rosenfeld, MD, Michael R. Sperling, MD, Sarah Mizne, PharmD, and Marc Kamin, MD

Neurology ${ }^{\circledR}$ 2020;94:e2311-e2322. doi:10.1212/WNL.0000000000009530

\section{Abstract}

\section{Objective}

To evaluate the efficacy and safety of adjunctive cenobamate $200 \mathrm{mg} / \mathrm{d}$ in patients with uncontrolled focal (partial-onset) seizures despite treatment with 1 to 3 antiepileptic drugs.

\section{Methods}

In this multicenter, double-blind, placebo-controlled study, adults 18 to 65 years of age with focal seizures were randomized 1:1 (cenobamate:placebo) after an 8-week baseline period. The 12-week double-blind treatment period consisted of a 6-week titration phase and a 6-week maintenance phase. The primary outcome was percent change in seizure frequency (from baseline) per 28 days during double-blind treatment.

\section{Results}

Two hundred twenty-two patients were randomized; 113 received cenobamate and 109 received placebo; and $90.3 \%$ and $90.8 \%$ of patients, respectively, completed double-blind treatment. Median baseline seizure frequency was 6.5 in 28 days (range 0-237). Compared to placebo, cenobamate conferred a greater median percent seizure reduction $(55.6 \%$ vs $21.5 \%$; $p$ $<0.0001)$ The responder rate ( $\geq 50 \%$ reduction in seizure frequency) was $50.4 \%$ for cenobamate and $22.2 \%$ for placebo $(p<0.0001)$. Focal seizures with motor component, impaired awareness, and focal to bilateral tonic-clonic seizures were significantly reduced with cenobamate vs placebo. During maintenance, $28.3 \%$ of cenobamate-treated and $8.8 \%$ of placebotreated patients were seizure-free. Treatment-emergent adverse events reported in $>10 \%$ in either group (cenobamate vs placebo) were somnolence $(22.1 \%$ vs $11.9 \%)$, dizziness $(22.1 \%$ vs $16.5 \%)$, headache ( $12.4 \%$ vs $12.8 \%)$, nausea ( $11.5 \%$ vs $4.6 \%)$, and fatigue (10.6\% vs $6.4 \%)$.

\section{Conclusion}

Adjunctive treatment with cenobamate $200 \mathrm{mg} / \mathrm{d}$ significantly improved seizure control in adults with uncontrolled focal seizures and was well tolerated.

\section{ClinicalTrials.gov identifier}

NCT01397968.

\section{Classification of evidence}

This study provides Class I evidence that, for patients with uncontrolled focal seizures, adjunctive cenobamate reduces seizures.

\author{
Correspondence \\ Dr. Chung \\ steve.chung@ \\ bannerhealth.com
}

\section{MORE ONLINE \\ $\rightarrow$ Class of Evidence \\ Criteria for rating therapeutic and diagnostic studies \\ NPub.org/coe}

\section{CME Course}

NPub.org/cmelist 


\section{Glossary}

$\mathrm{AE}=$ adverse event; AED = antiepileptic drug; ITT = intention-to-treat; TEAE = treatment-emergent adverse event; VNS = vagus nerve stimulation.

Despite the increased availability of new antiepileptic drugs (AEDs) over the past 25 years, seizures remain uncontrolled in a substantial portion $(>30 \%)$ of patients with epilepsy. ${ }^{1-4}$ In addition, once an initial AED fails to suppress seizures, the likelihood of achieving seizure control with each subsequent AED regimen diminishes markedly (50.5\% with the first AED, $11.6 \%$ with the second, and $4.1 \%$ with the third). ${ }^{1}$ Thus, there is a need for new AEDs that can improve seizure control, particularly in patients with refractory epilepsy.

Cenobamate is a novel tetrazole alkyl carbamate derivative recently approved in the United States for the treatment of adults with focal (partial-onset) seizures. ${ }^{5}$ The mechanism of action of cenobamate is thought to involve reduction of repetitive neuronal firing by enhancing the fast and slow inactivation of sodium channels and by inhibiting the persistent component of the sodium current. ${ }^{6}$ It has also shown positive allosteric modulation of 6 subtypes of the GABA ion channel. ${ }^{7}$ Cenobamate has demonstrated broad-spectrum anticonvulsant activity in animal epilepsy and seizure models, ${ }^{5}$ including pentylenetetrazol kindling and maximal electroshock seizure models; a proof-of-concept study demonstrated suppression of the photoparoxysmal response in patients with photosensitive epilepsy. ${ }^{8} \mathrm{~A}$ randomized, double-blind, placebo-controlled study was conducted to assess the efficacy and safety of adjunctive cenobamate 200 $\mathrm{mg} / \mathrm{d}$ in adults with uncontrolled focal seizures (YKP3089C013; clinicaltrials.gov NCT01397968).

\section{Methods}

\section{Classification of evidence}

The primary research question was to investigate whether adjunctive cenobamate would significantly reduce the percent seizure frequency per 28 days compared with placebo. This study provides Class I evidence that, for patients with uncontrolled focal seizures, adjunctive cenobamate reduces seizures.

\section{Standard protocol approvals, registrations, and patient consents}

This study (clinicaltrials.gov identifier NCT01397968) was performed in accordance with the International Conference on Harmonisation Good Clinical Practice guidelines, as well as any applicable country-specific regulations. The study protocol was approved by an independent ethics committee or institutional review board according to local regulations at each site. Written informed consent was obtained from each patient before study participation.

\section{Participants}

Patients were adults 18 to 65 years of age with a diagnosis of treatment-resistant focal (partial-onset) epilepsy, as defined by the International League Against Epilepsy."10 Patients must have had an EEG consistent with the diagnosis of focal epilepsy and a CT or MRI scan performed within the last 5 years. All seizure diagnoses were confirmed by an independent review from The Epilepsy Study Consortium. Patients must have been taking 1 to 3 AEDs at stable doses for at least 12 weeks before randomization. Within the 2 months before randomization (baseline period), patients were required to have $\geq 3$ focal aware (simple partial) seizures with motor component, including aphasia and other observable symptoms; focal impaired awareness (complex partial); or focal to bilateral tonic-clonic (secondarily generalized) seizures per month, plus no consecutive 21-day seizure-free period. Vagus nerve stimulation (VNS) was permitted and was not counted as an AED. VNS had to have been implanted at least 5 months before randomization, and the stimulation parameters must have remained stable for at least 4 weeks before the screening (baseline) visit. Adjustment of VNS parameters was not permitted during the study.

Patients taking vigabatrin within the past year, felbamate for $<18$ continuous months, or intermittent rescue benzodiazepines more than once a month within the past month were excluded, as were patients taking phenytoin or phenobarbital because of the potential for drug-drug interaction with cenobamate inhibition of CYP2C19. ${ }^{11,12}$ Patients with a history of status epilepticus within the past year, history of alcoholism or drug abuse within the past 2 years, clinically significant psychiatric illness, active suicidal ideation within the past 6 months or history of suicide attempt in the past 2 years, or $>2$ allergic reactions to an AED or 1 serious hypersensitivity reaction were also excluded.

\section{Study design, randomization, and blinding}

This phase 2, multicenter, randomized, double-blind, placebocontrolled, parallel-group study was conducted at 40 centers in the United States, India, Republic of Korea, and Poland. Before randomization, patients underwent a screening visit and a baseline period ( 4 or 8 weeks, depending on availability of 4 weeks of adequate retrospective seizure diary at screening) to assess seizure frequency. Eligible patients were randomized (1:1) via an interactive web response system to receive placebo or cenobamate at a target dose of $200 \mathrm{mg}$ once daily, stratified by country, and entered a 12 -week doubleblind treatment period that included a 6-week titration phase and a 6-week maintenance phase. Randomization codes were computer generated by a statistician with stratification for country. Patients, study personnel, and investigators 
remained blinded to the randomized treatment assignment during the double-blind study.

During the titration phase, patients received an initial dose of cenobamate $50 \mathrm{mg}$ once daily or matching daily placebo and were uptitrated by $50 \mathrm{mg} / \mathrm{d}$ every 2 weeks to a target dose of $200 \mathrm{mg} / \mathrm{d}$ at the beginning of the maintenance phase. If a patient could not tolerate the next higher dose, the patient was to continue on the current dose or have the dose reduced. During the 6-week maintenance phase, patients could not exceed the maximum dose level of study drug attained during titration. Dose reductions for tolerability could occur throughout the double-blind treatment period. No dose changes to concomitant AEDs were allowed during the double-blind study. Patients were to continue taking their allowed concomitant AEDs without any dose changes throughout the double-blind treatment period. At the end of double-blind treatment, patients either were tapered off study drug before transitioning to optional open-label treatment or were allowed to directly convert to open-label cenobamate without being tapered off if medically warranted (following protocol amendment).

\section{Study outcomes}

Seizure frequency and type were recorded in patient diaries. The primary efficacy outcome was percent change from baseline in focal seizure frequency per 28 days during the double-blind treatment period (both titration and maintenance phases). Secondary outcomes included responder rate (response defined as a $\geq 50 \%$ reduction in seizure frequency) and assessment of seizure frequency by seizure type: focal aware with motor component, focal impaired awareness, or focal to bilateral tonic-clonic.

Safety outcomes included the incidence of treatmentemergent adverse events (TEAEs); serious adverse events (AEs); treatment discontinuations; and changes from baseline in vital signs, physical and neurologic examinations, clinical laboratory evaluations, and 12-lead ECGs. Any patient who reported a rash was evaluated for drug hypersensitivity. Columbia Suicide Severity Rating Scale questionnaires were also administered to monitor suicidality.

\section{Statistical analysis}

The intention-to-treat (ITT) population included all randomized patients who had taken at least 1 dose of study drug and had at least 1 efficacy evaluation. The completer population included all ITT patients who completed the doubleblind treatment period. The safety population included all randomized patients who took a single dose of study drug or placebo.

Assuming an SD of $40 \%$, a sample size of 100 participants in each group would be required to detect a $16 \%$ treatment difference in percent seizure frequency at a 2 -sided significance level of 0.05 with $80 \%$ power using a Wilcoxon ranksum test. Seizure frequency during the baseline and 12-week treatment periods was calculated by summing the number of seizures in each period and dividing by the total duration (days), excluding days with no available diary data, and multiplying by 28 to normalize to a monthly rate. The analysis of baseline seizure frequency used a total duration of 56 days; thus, some patients may have a calculated baseline rate of $<3$ seizures per 28 days despite meeting the inclusion criteria of $\geq 3$ seizures per month. A prespecified model-fitting strategy was applied to examine and understand the distribution characteristics of the primary outcome data. Because of the nonparametric nature of the data, the percent change in seizure frequency from baseline was analyzed with a Wilcoxon rank-sum test. The $\geq 50 \%$ responder rate was analyzed with a logistic regression model including treatment, country, baseline seizure frequency, and treatment by study site interaction. Adjusted odds ratio and $95 \%$ confidence interval (Wald $\chi^{2}$ ) for the estimated odds ratio were used to estimate treatment effect of cenobamate relative to placebo during the double-blind period. Post hoc analyses were conducted to determine additional responder rates at $75 \%, 90 \%$, and $100 \%$ (i.e., seizure-free) during the maintenance phase. Seizure frequency over time was analyzed post hoc at sequential 4-week intervals (weeks 1-4, weeks 5-8, etc) with comparisons between treatment groups with a Wilcoxon rank-sum test.

Safety and tolerability were analyzed descriptively. AEs were coded according to the Medical Dictionary for Regulatory Activities (version 16.0).

\section{Data availability}

The data for the analyses described in this paper are available by request from the author, investigators, or SK Life Science, Inc, the company sponsoring the clinical development of cenobamate for the treatment of focal epilepsy.

\section{Results}

\section{Patients}

The double-blind study was conducted from July 2011 to June 2013. A total of 222 patients (median age 37 years, range $18-61$ years) were randomized to receive cenobamate $200 \mathrm{mg} / \mathrm{d}$ ( $\mathrm{n}=$ $113)$ or placebo $(n=109)$ (figure 1$)$ and entered the titration phase. All patients received at least 1 treatment dose and were included in the safety population. All patients except 1 in the placebo group had at least 1 efficacy evaluation and were included in the ITT population; 201 patients completed the study, including $90.3 \%$ (102 of 113) of patients in the cenobamate group and $90.8 \%$ (99 of 109) of patients in the placebo group. The highest dose of cenobamate achieved during treatment by patients who completed the study was $200 \mathrm{mg} /$ d (66.7\%, 68 of 102), $150 \mathrm{mg} / \mathrm{d}(24.5 \%, 25$ of 102), $100 \mathrm{mg} /$ $\mathrm{d}(4.9 \%, 5$ of 102$)$, and $50 \mathrm{mg} / \mathrm{d}(3.9 \%, 4$ of 102). Fifty-nine patients $(57.8 \%, 59$ of 102$)$ completed the study on the $200-\mathrm{mg}$ cenobamate target dose. Study discontinuation rates among all randomized patients were similar in the cenobamate $(\mathrm{n}=11$, 9.7\%) and placebo $(n=10,9.2 \%)$ groups, with AEs reported as the primary reason for withdrawal in 4 patients in each treatment group. 


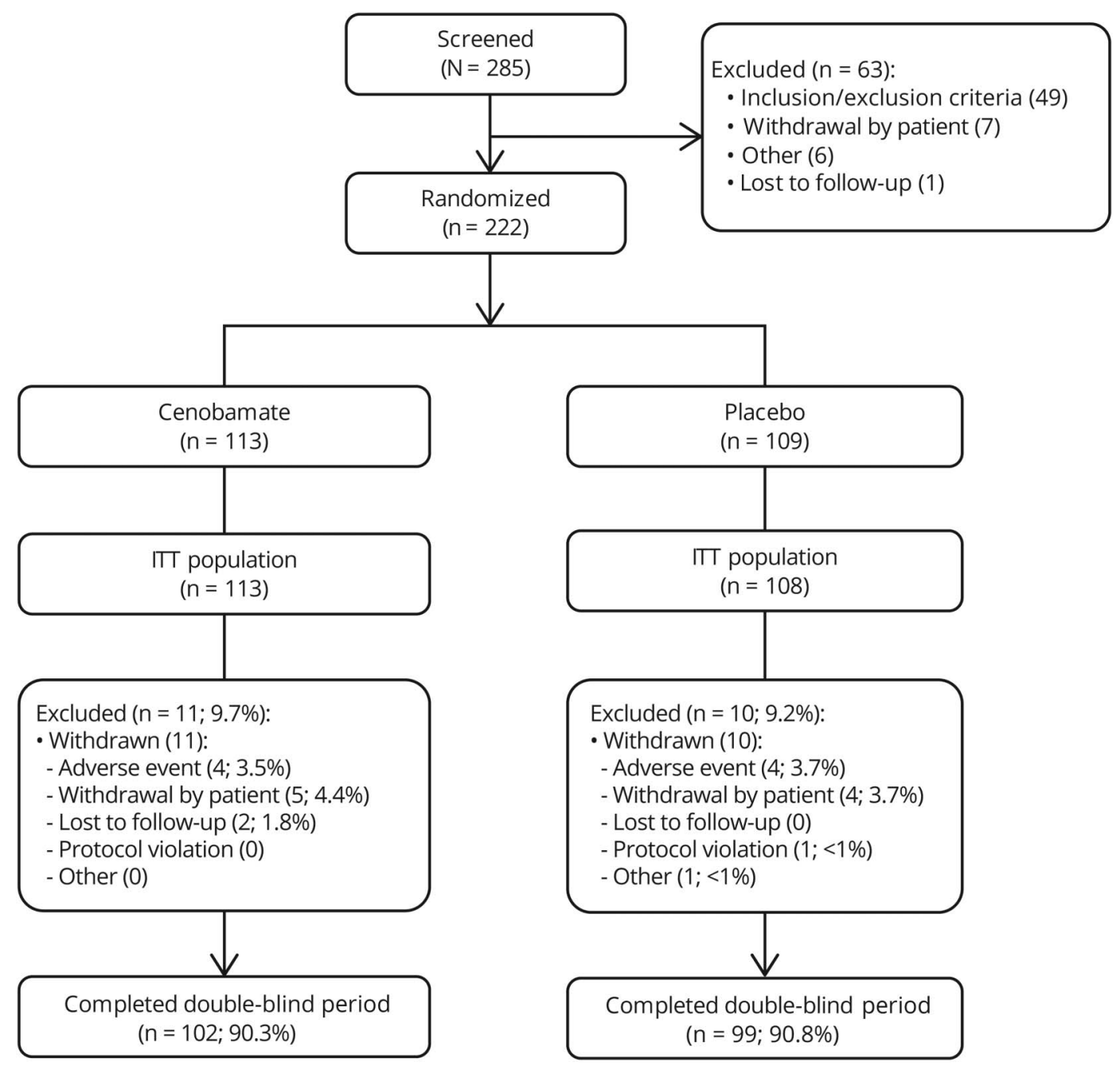

ITT = intention-to-treat.

Baseline patient demographics and epilepsy characteristics were similar in each treatment group (table 1). Although 9 patients had a history of generalized seizures, all patients had a diagnosis of drug-resistant focal epilepsy at the time of study enrollment. A substantial portion of patients were taking 2 (47.3\%) or $3(38.7 \%)$ concomitant AEDs. The most frequently used concomitant AED was levetiracetam (46.8\%), followed by carbamazepine (36.5\%), lamotrigine $(33.8 \%)$, and oxcarbazepine (22.5\%) (table 1).

\section{Efficacy}

In the ITT population, median focal seizure frequency per 28 days during double-blind treatment decreased from 7.5 at baseline to 3.8 for the cenobamate group $(n=113)$ and from 5.5 at baseline to 5.0 for the placebo group $(n=108)$. The median percent reduction in seizure frequency per 28 days (primary outcome) was $55.6 \%$ and $21.5 \%$ for cenobamateand placebo-treated patients, respectively $(p<0.0001)$ (figure $2 \mathrm{~A}$ ). The $\geq 50 \%$ responder rate was also significantly greater for patients treated with cenobamate $(50.4 \%)$ vs placebo (22.2\%) (odds ratio 3.94, 95\% confidence interval 2.14-7.24; $p<0.0001$ ) (figure 2B).

Within each focal seizure subtype, the median percent reduction in 28-day seizure frequency from baseline for the cenobamate and placebo groups (ITT population) was $76.3 \%$ and $27.8 \%(p=0.0448)$, respectively, for patients with focal aware motor seizures, $55.6 \%$ and $21.1 \%(p=0.0009)$ for patients with focal impaired awareness seizures, and $77.0 \%$ and $33.0 \%(p=0.0117)$ for patients with focal to bilateral tonic-clonic seizures (figure 3 ).

During the 6-week maintenance phase, significantly greater percentages of patients (post hoc analysis) achieved seizure reduction rates of $\geq 75 \%$ ( $38.7 \%$ vs $20.6 \%$; $p=0.0019$ ), $\geq 90 \%$ ( $34.0 \%$ vs $8.8 \% ; p<0.0001$ ), and $100 \%$ (28.3\% vs $8.8 \% ; p=0.0001)$ with cenobamate compared with placebo (figure 4A). Similar results were shown in the completer 
Table 1 Patient demographic and baseline clinical characteristics (safety population)

\begin{tabular}{|c|c|c|}
\hline & $\begin{array}{l}\text { Cenobamate } \\
(n=113)\end{array}$ & $\begin{array}{l}\text { Placebo } \\
(n=109)\end{array}$ \\
\hline Age, median (minimum, maximum), y & $36(18,61)$ & $38(18,59)$ \\
\hline Female, $\mathrm{n}(\%)$ & $58(51.3)$ & $51(46.8)$ \\
\hline \multicolumn{3}{|l|}{ Race, $n(\%)$} \\
\hline Caucasian/white & $57(50.4)$ & $58(53.2)$ \\
\hline Asian & $49(43.4)$ & $45(41.3)$ \\
\hline Black/African American & $3(2.7)$ & $2(1.8)$ \\
\hline Other or unknown & $4(3.5)$ & $4(3.7)$ \\
\hline Time since diagnosis, median (minimum, maximum), mo & $239.4(28,630)$ & $252.8(29,729)$ \\
\hline Baseline focal seizure frequency $(28 \mathrm{~d}){ }^{\mathrm{b}}$ median (minimum, maximum) & $7.5\left(0,{ }^{a} 187\right)$ & $5.5(2,237)$ \\
\hline \multicolumn{3}{|l|}{ Seizure types by history, ${ }^{c} \mathrm{n}(\%)$} \\
\hline Focal seizures & $106(93.8)$ & $102(93.6)$ \\
\hline Focal aware nonmotor & 18 (15.9) & $16(14.7)$ \\
\hline Focal impaired awareness & $83(73)$ & $92(84)$ \\
\hline Focal aware motor & $31(27.4)$ & $25(22.9)$ \\
\hline Focal to bilateral tonic-clonic & $73(64.6)$ & $67(61.5)$ \\
\hline \multicolumn{3}{|l|}{ Generalized } \\
\hline Nonmotor (absence) & $1(0.9)$ & 0 \\
\hline Motor tonic & $1(0.9)$ & $2(1.8)$ \\
\hline Motor tonic-clonic & $2(1.8)$ & $3(2.8)$ \\
\hline Febrile & $6(5.3)$ & $5(4.6)$ \\
\hline \multicolumn{3}{|l|}{ No. of background/concomitant AEDs, $n(\%)$} \\
\hline 1 & $19(16.8)$ & $12(11.0)$ \\
\hline 2 & $53(46.9)$ & $52(47.7)$ \\
\hline 3 & $41(36.3)$ & $45(41.3)$ \\
\hline \multicolumn{3}{|l|}{ Background/concomitant AEDs ( $\geq 10 \%$ of patients), $n(\%)$} \\
\hline Levetiracetam & $51(45.1)$ & $53(48.6)$ \\
\hline Lamotrigine & $41(36.3)$ & $34(31.2)$ \\
\hline Carbamazepine & $38(33.6)$ & $43(39.4)$ \\
\hline Lacosamide & $27(23.9)$ & $21(19.3)$ \\
\hline Topiramate & $25(22.1)$ & $21(19.3)$ \\
\hline Oxcarbazepine & $24(21.2)$ & 26 (23.9) \\
\hline Clobazam & $22(19.5)$ & $16(14.7)$ \\
\hline Valproate sodium & $17(15.0)$ & $20(18.3)$ \\
\hline Valproic acid & $13(11.5)$ & $11(10.1)$ \\
\hline
\end{tabular}

Abbreviation: $\mathrm{AED}=$ antiepileptic drug.

a One patient had only focal aware nonmotor seizures during baseline and was randomized and treated in error. This patient was counted in the intention-totreat and safety populations.

${ }^{\mathrm{b}}$ Baseline seizure frequency $=$ number of seizures over baseline period ( 56 days before study day 1 ) divided by number of days in the interval multiplied by 28

'Patients may be reported in $>1$ category. 

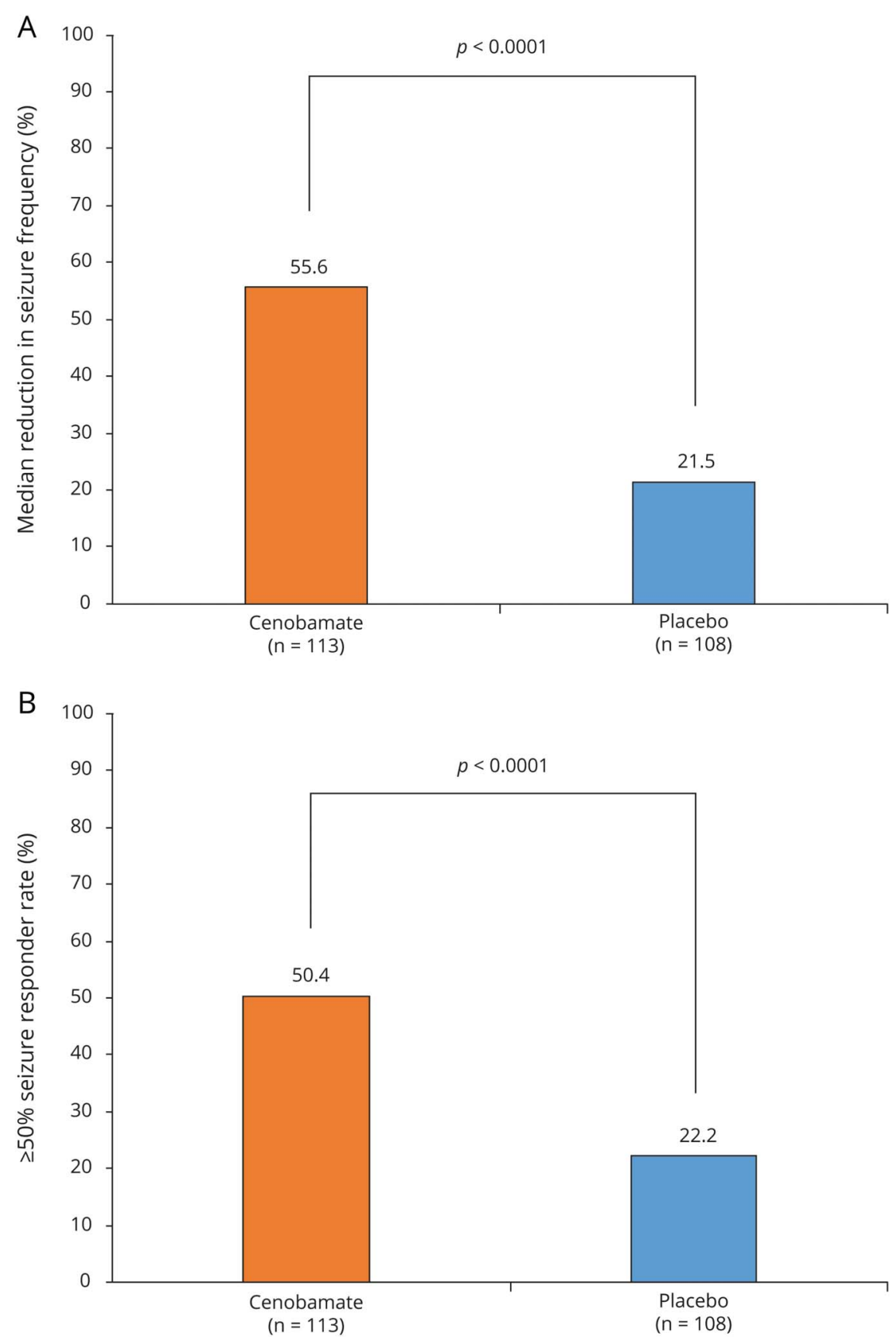

(A) Median percent reduction in seizure frequency normalized to 28-day rate. (B) Responder rates during the double-blind period. Responder defined as $\geq 50$ reduction in seizure frequency. ITT = intention-to-treat.

population (figure 4B). Among cenobamate-treated patients in the completer population, $27.5 \%$ (28 of 102 ) achieved $100 \%$ seizure reduction during the 6-week maintenance phase (post hoc analysis).

In the assessment of patients who completed the study, the median percent change in seizure frequency decreased during the first 4 weeks of titration by $40.6 \%$ from baseline compared with $14.3 \%$ for placebo $(p=0.001$ ) (figure 5). Significantly greater reductions from baseline occurred over each subsequent 4-week interval for cenobamate vs placebo.

\section{Safety}

During the 12-week treatment period, TEAEs were reported in 86 of 113 cenobamate-treated patients (76.1\%) and 69 of 109 placebo-treated patients $(63.3 \%)$. TEAEs reported in at least $5 \%$ of patients in either treatment group are shown in table 2; all except anxiety and headache occurred more frequently in the cenobamate group. The most frequently ( $>10 \%)$ reported TEAEs for cenobamate were somnolence (22.1\%), dizziness (22.1\%), headache (12.4\%), nausea $(11.5 \%)$, and fatigue $(10.6 \%)$. For placebo, they were dizziness $(16.5 \%)$, headache $(12.8 \%)$, and somnolence $(11.9 \%)$, 


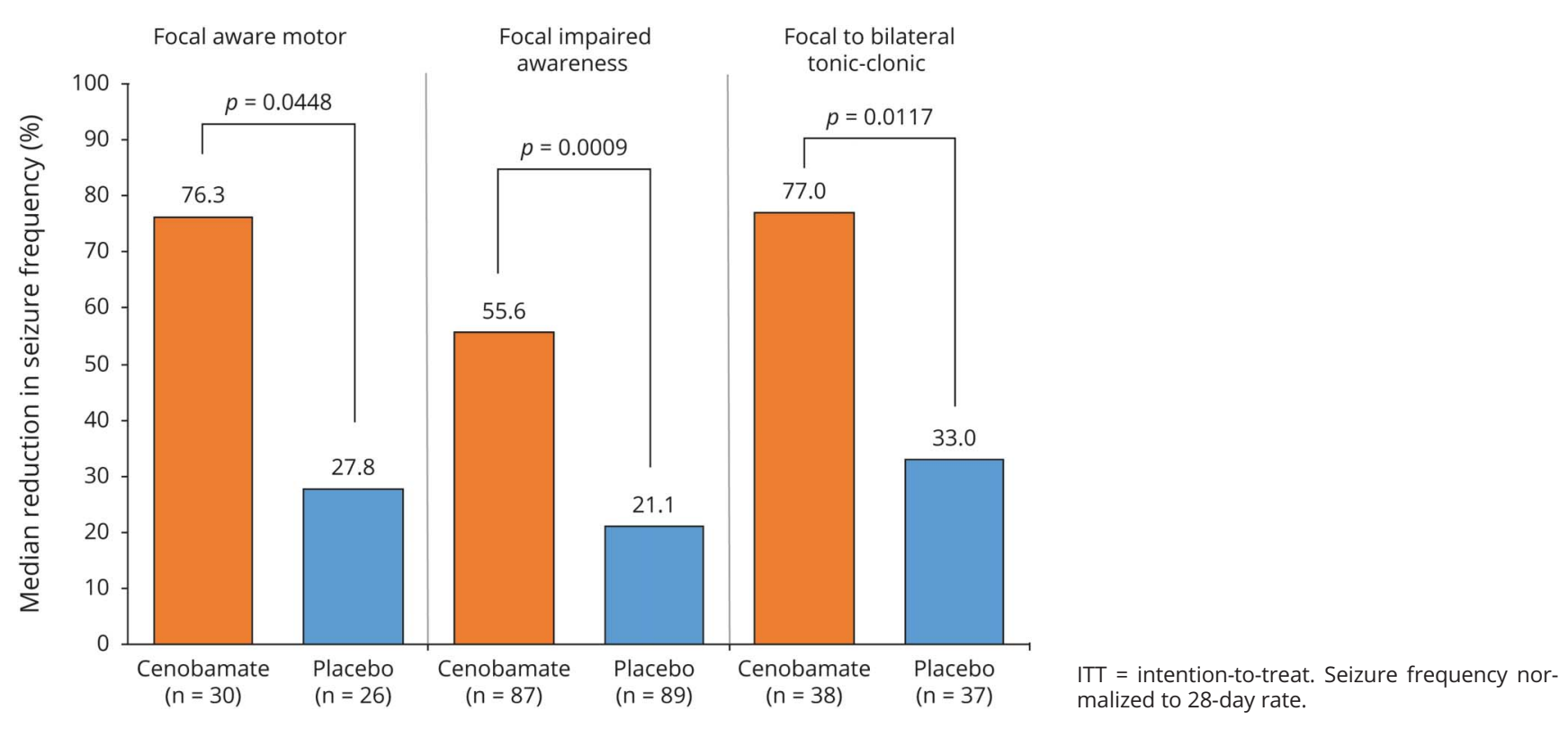

(table 2). Most TEAEs were mild or moderate in severity (cenobamate: mild or moderate $74.3 \%$, severe $1.8 \%$; placebo: mild or moderate $56.9 \%$, severe $6.4 \%$ ). One TEAE of suicidal ideation was reported in each treatment group. Columbia Suicide Severity Rating Scale responses did not reveal any increases in suicidal ideation, intensity, or behavior from baseline with cenobamate. Among infectious TEAEs, only urinary tract infections ( $8.0 \%$ cenobamate vs $1.8 \%$ placebo) and nasopharyngitis (6.2\% cenobamate vs $0.9 \%$ placebo) occurred with at least a 5-percentage point difference between groups. Treatment-related TEAEs occurring in $>5 \%$ of cenobamate-treated patients with a $\geq 5 \%$ difference over the placebo group included somnolence $(22.1 \%$ vs $10.1 \%)$, dizziness $(20.4 \%$ vs $13.8 \%)$, balance disorder ( $7.1 \%$ vs $0.9 \%)$, and nystagmus (9.7\% vs $0 \%)$.

In the cenobamate group, 5 patients experienced 8 AEs that led to a treatment discontinuation (tachycardia, gastroesophageal reflux disease, drug hypersensitivity, nystagmus, aggression, depression, and dyspnea). In the placebo group, 3 patients experienced 8 AEs that led to a treatment discontinuation (altered state of consciousness, ataxia, dyskinesia, grand mal convulsion, partial seizure, somnolence, status epilepticus, and tremor). Serious TEAEs were reported in 2 cenobamatetreated patients $(\mathrm{n}=1$ drug hypersensitivity reaction, $\mathrm{n}=1$ urinary tract infection) and 4 placebo-treated patients $(\mathrm{n}=2$ status epilepticus, $\mathrm{n}=1$ convulsion, $\mathrm{n}=1$ hospitalization for coronary angiography performed because of chest pain and ECG abnormalities). A drug hypersensitivity reaction of moderate intensity was reported in a patient who received a single dose of $50 \mathrm{mg}$ cenobamate and was considered related to treatment. The reaction began on day 1 of treatment and was characterized by reddening of palms and soles and itching of ears. Study treatment was discontinued; oral antihistamines and corticosteroids were administered; and the patient recovered after 22 days. No other serious dermatologic TEAEs, including cases of drug reaction with eosinophilia and systemic symptoms or Stevens-Johnson syndrome, were reported. No deaths occurred during the double-blind treatment period. One sudden unexplained death in epilepsy occurred in a patient before randomization.

There were no clinically meaningful trends in changes from baseline in mean laboratory values, physical and neurologic examinations, vital signs, or ECGs.

\section{Discussion}

In this multicenter randomized study, treatment with adjunctive cenobamate led to statistically significant reductions in focal seizure frequency with few withdrawals due to AEs. Both the median percent reduction in seizure frequency relative to placebo per 28 days ( $55.6 \%$ vs $21.5 \%$, primary outcome) and responder rates relative to placebo observed with cenobamate in this study compare favorably to published rates from individual and pooled randomized clinical studies of other adjunctive AEDs. ${ }^{13-28}$ A significant positive benefit with cenobamate was observed in all assessed focal seizure types, with a large median percent reduction per 28 days noted among patients with focal to bilateral tonic-clonic seizures ( $77.0 \%$ vs $33 \%$ for placebo). The reduction in focal to bilateral tonic-clonic seizures is noteworthy given that persistent generalized tonic-clonic seizures are associated with an increased risk for sudden unexpected death in epilepsy. ${ }^{29}$ Seizure reduction with cenobamate was observed relatively early, within the first 4 weeks of treatment during the titration 
Figure 4 Post hoc responder rates during the maintenance phase
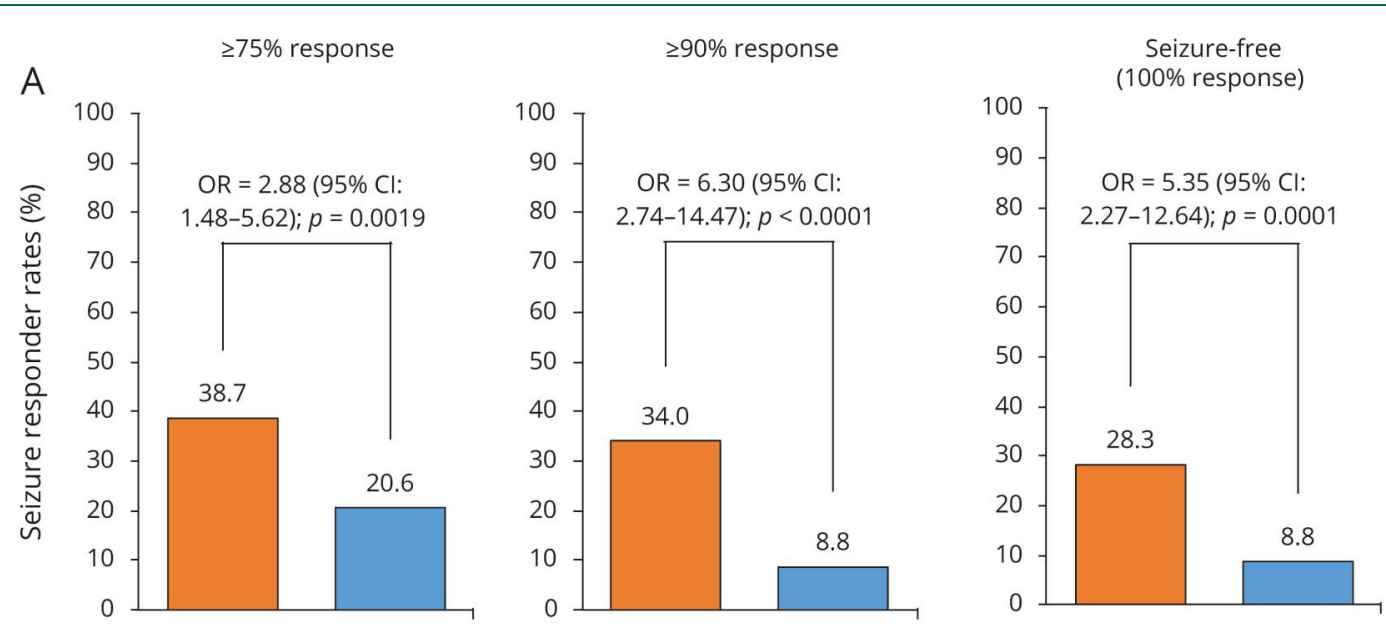

Cenobamate $(n=106)$

Placebo $(n=102)$

B
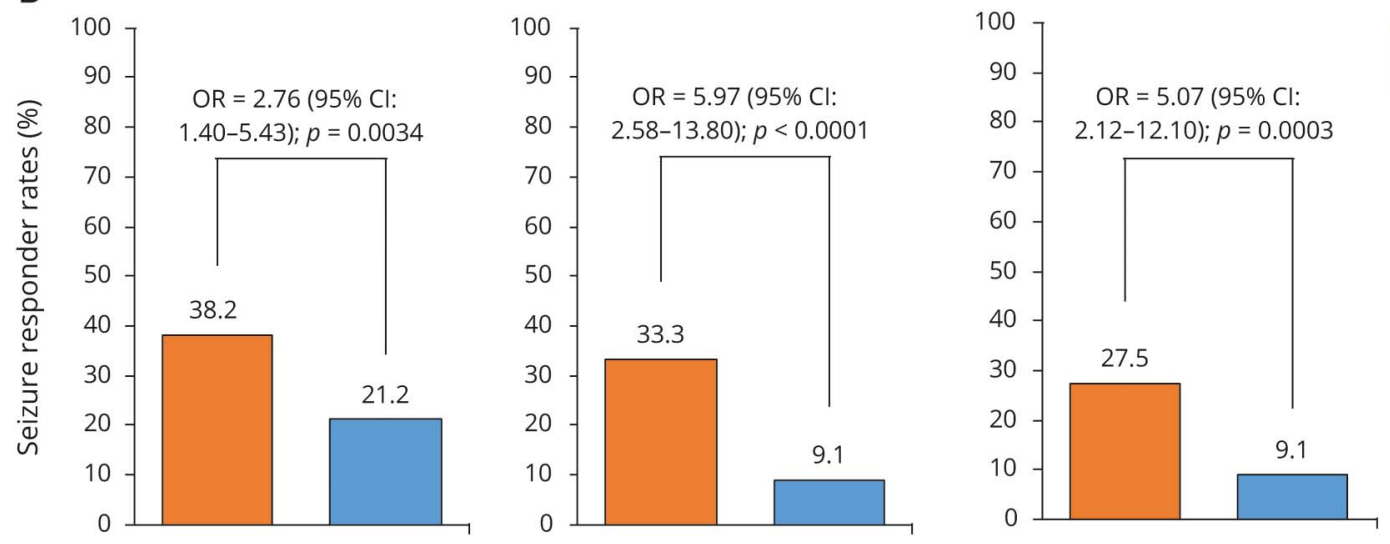

Cenobamate $(n=102)$

Placebo $(n=99)$

(A) Responder rates during the 6-week maintenance phase (intention-to-treat population who took $\geq 1$ dose of study drug during the maintenance phase $\mathrm{n}=$ 208). (B) Responder rates during the 6 -week maintenance phase (completer population $n=201$ ). Responder defined as $\geq 75 \%, 90 \%$, or $100 \%$ reduction in seizure frequency during the maintenance phase. $\mathrm{Cl}$ = confidence interval; OR = odds ratio.

phase (dosages $50-100 \mathrm{mg} / \mathrm{d}$ ), with a median percent reduction in seizure frequency of $40.6 \%$ during this time vs $14.3 \%$ for placebo.

Cenobamate was generally well tolerated as adjunctive therapy, as shown by the low (and similar) rate of withdrawals due to AEs between the cenobamate and placebo groups (only 4 patients in each group). Although the majority of patients tolerated the 200-mg/d target dose of cenobamate, approximately one-third (37\%) did not reach this dose because there was no forced titration. Higher withdrawal rates have been reported with other AED studies, including those that used forced titration schedules. $^{20,30,31}$ The use of flexible titration may have contributed to the relatively low study discontinuation rate with cenobamate. This is an important aspect of the study in that a number of AED studies have demonstrated good efficacy at doses that were subsequently not tolerated in the clinic. The facts that patients in this study remained on the dose that they felt was tolerable and few dropped out mean, we hope, that the efficacy demonstrated can be recapitulated in the clinic.
Ongoing, even infrequent seizures, as few as 1 in the previous 5 years, have been shown to negatively affect patients, ${ }^{32}$ underscoring the importance of reporting seizure freedom rates in AED clinical studies. ${ }^{33}$ The post hoc analyses of additional seizure response rates, including $100 \%$ seizure reduction, used data from the maintenance phase. Reporting seizure responses during the maintenance phase more accurately reflects steady-state dosing levels at the target dose compared to using the entire treatment period, including the titration phase. This, however, does result in a relatively brief monitoring period ( 6 weeks) during the maintenance phase. Nevertheless, there were high $\geq 75 \%, \geq 90 \%$, and $100 \%$ seizure reduction rates with cenobamate treatment compared with placebo. In particular, the percentage of seizure-free patients (28.3\%) with cenobamate treatment was a noteworthy finding given that the percentage in the placebo group was $8.8 \%$ and $>80 \%$ of patients in this study were taking $\geq 2$ concomitant AEDs. A similar percentage of seizure-free patients was also noted in the completer population. Analyses that include those patients who complete the study and do not allow study discontinuations resulting from AEs to count as seizure-free 
Figure 5 Median percent reduction from baseline in seizure frequency per 28 days over sequential 4-week intervals (completer population)

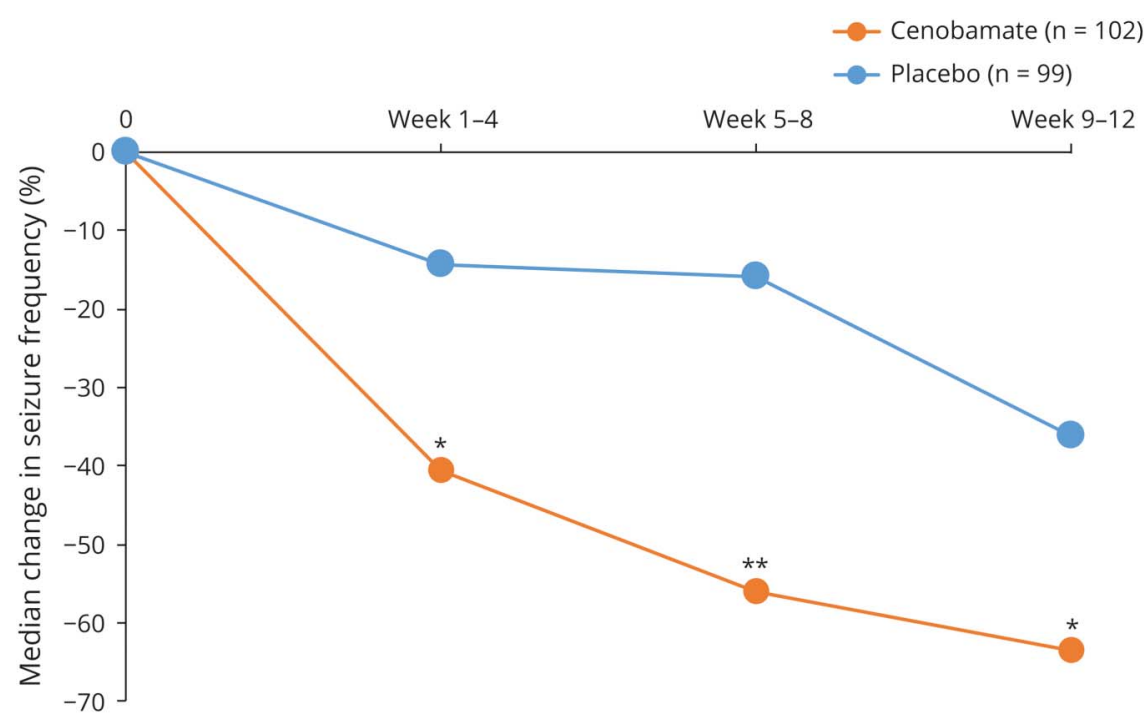

${ }^{*} p=0.001,{ }^{* *} p<0.001$ vs placebo.

may be more informative. ${ }^{34}$ When a previously suggested pragmatic ITT approach is used ${ }^{34}$ that divides the number of seizure-free completers by the ITT population, $24.8 \%$ of patients ( 28 of 113 ) in the cenobamate group achieved $100 \%$ seizure reduction during the maintenance phase compared with $8.3 \%$ (9 of 108) in the placebo group.

The 6-week maintenance duration in the current study makes it difficult to directly compare rates across studies. ${ }^{17-26}$ Furthermore, it is not yet known how long patients in this study will remain seizure-free or how long significant seizure control will be maintained because the open-label study is still ongoing. Nonetheless, these data offer an important first look at the clinical efficacy of cenobamate and can serve as a point of reference for future studies and analyses.

AEDs are commonly associated with AEs, most notably CNSrelated AEs, and polytherapy can increase the risk of AEs. ${ }^{35}$ In this study, the most common TEAEs associated with cenobamate were CNS related, including somnolence and dizziness; however, the majority were mild/moderate in severity and rarely led to treatment discontinuation. The rate of serious AEs during the double-blind treatment period was low, particularly in the cenobamate group. One serious drug hypersensitivity event was reported in a patient receiving cenobamate, which resolved with discontinuation. No other serious cutaneous reactions were reported during the doubleblind treatment period in this study. Idiosyncratic AEs that have been reported with AEDs, including cutaneous reactions, can be severe and life-threatening. ${ }^{36,37}$ During early clinical development, among the first 953 participants exposed to cenobamate, 3 confirmed cases of drug reaction with eosinophilia and systemic symptoms were reported. ${ }^{38} \mathrm{~A}$ large ongoing multicenter phase 3 safety study is investigating the use of adjunctive cenobamate at a lower starting dose $(12.5 \mathrm{mg})$ and slower titration rate, with increases every 2 weeks $(25,50$, 100, 150, and $200 \mathrm{mg}$ ) (clinicaltrials.gov NCT02535091).

While the precise mechanism of action of cenobamate is not fully known, assessments have characterized cenobamate as a modulator of voltage-gated sodium ion channels and GABA currents. ${ }^{6,7}$ In particular, it has been shown to reduce repetitive neuronal firing by enhancing fast and slow inactivation of sodium channels and by inhibiting the persistent component of the sodium current. Further investigation is needed to determine how the potentially unique combination of mechanisms of action may play a role in the clinical efficacy and manageable tolerability profile of cenobamate despite the use of various concomitant AEDs, including other sodium channel blockers. In this study, somewhat higher percentages of TEAEs occurred among cenobamate-treated patients taking sodium channel blockers compared to those not taking them. Among those taking sodium channel blockers, TEAEs occurred in $79.1 \%$ (68 of 86 ) of cenobamate-treated patients (relative to $62.5 \%$ [ 55 of 88] for placebo); among those not taking sodium channel blockers, TEAEs occurred in $74.1 \%$ (20 of 27) of cenobamate-treated patients (relative to $71.4 \%$ [15 of 21] for placebo). Given that the number of patients was small and unbalanced between groups ( $n=86$ vs $n=27)$, it is difficult to make definitive conclusions about tolerability in conjunction with sodium channel blockers. Data from the large phase 3 safety study, which allows dose adjustment of concomitant AEDs, should provide recommendations for the real-world management of patients taking cenobamate.

Study limitations include the relatively short treatment duration (12 weeks, with 6-week maintenance phase); however, analysis of patients in the ongoing open-label extension phase 
Table 2 Summary of TEAEs (safety population)

\begin{tabular}{|c|c|c|}
\hline & $\begin{array}{l}\text { Cenobamate } \\
(n=113), n(\%)\end{array}$ & $\begin{array}{l}\text { Placebo } \\
(n=109), n(\%)\end{array}$ \\
\hline Any TEAE & $86(76.1)$ & $69(63.3)$ \\
\hline Treatment-related TEAEs & $67(59.3)$ & $50(45.9)$ \\
\hline Serious TEAEs & $2(1.8)$ & $4(3.7)$ \\
\hline \multicolumn{3}{|l|}{ TEAEs $\geq 5 \%$} \\
\hline Somnolence & $25(22.1)$ & $13(11.9)$ \\
\hline Dizziness & $25(22.1)$ & $18(16.5)$ \\
\hline Headache & $14(12.4)$ & $14(12.8)$ \\
\hline Nausea & $13(11.5)$ & $5(4.6)$ \\
\hline Fatigue & $12(10.6)$ & $7(6.4)$ \\
\hline Nystagmus & $11(9.7)$ & 0 \\
\hline Balance disorder & $9(8.0)$ & $1(0.9)$ \\
\hline Urinary tract infection & $9(8.0)$ & $2(1.8)$ \\
\hline $\begin{array}{l}\text { Upper respiratory tract } \\
\text { infection }\end{array}$ & $8(7.1)$ & $5(4.6)$ \\
\hline Tremor & $7(6.2)$ & $3(2.8)$ \\
\hline Nasopharyngitis & $7(6.2)$ & $1(0.9)$ \\
\hline Constipation & $6(5.3)$ & 0 \\
\hline Diarrhea & $6(5.3)$ & 0 \\
\hline Vomiting & $6(5.3)$ & $2(1.8)$ \\
\hline Anxiety & $1(0.9)$ & $6(5.5)$ \\
\hline
\end{tabular}

Abbreviation: TEAE = treatment-emergent adverse event.

Adverse events that occur up to 7 days after the patient's last dose of doubleblind study drug are included as TEAEs.

is anticipated and will provide additional insight into the long-term safety of adjunctive cenobamate. The treatmentrefractory nature of the patient population, the use of flexible dosing, and concomitant medications present additional challenges to the interpretation of these data but also can be seen as strengths in terms of the generalizability of the results. Other strengths of the study include the use of an independent panel to confirm the appropriate diagnosis and classification of epilepsy and the inclusion of clinically important efficacy assessments.

Adjunctive cenobamate demonstrated statistically significant improvements from baseline in median percent seizure frequency reduction per 28 days compared with placebo in patients with uncontrolled focal seizures. Additional significant improvement in several focal seizure types and in seizure freedom rates was also shown with cenobamate, and the treatment appeared to be well tolerated.

\section{Acknowledgment}

The authors thank Don Fallon, ELS, of MedVal Scientific Information Services, LLC (Princeton, NJ) for providing medical editing assistance, which was funded by SK Life Science, Inc. This manuscript was prepared according to the International Society for Medical Publication Professionals' "Good Publication Practice for Communicating CompanySponsored Medical Research: GPP3.”

\section{Study funding}

This study was funded by SK Life Science, Inc.

\section{Disclosure}

S.S. Chung is a consultant for Adamas, Eisai, SK Life Science, Inc, and UCB; is a speaker for Eisai, Greenwich Biosciences, Sunovion, and UCB; and received grant support from Engage, SK Life Science, Inc, and UCB. J.A. French receives New York University (NYU) salary support from the Epilepsy Foundation and for consulting work and/or attending Scientific Advisory boards on behalf of the Epilepsy Study Consortium for Acadia, Adamas, Addex, Aeonian, Alexza, Anavex, Axcella, Axovant, Biogen, BioMotiv/Koutif, Blackfynn, Bloom Science, Bridge Valley Ventures, Cavion, Cerebral Therapeutics, Cerevel, Clinilabs, Concert Pharmaceuticals, Covance, Crossject, CuroNZ, Eisai, Empatica, Engage, Epitel, GW Pharma, Idorsia, Impax, Ionis, J\&J Pharmaceuticals, Marinus, MonoSol Rx, Neurelis, Novartis, Otsuka, Ovid, Pfizer, Pfizer-Neusentis, Praxis, Redpin, Sage, Sancilio, Shire, SK Life Science, Inc, SpringWorks, Stoke, Sunovion, Supernus, Takeda, UCB, Ultragenyx, Upsher-Smith, Vyera, West Therapeutic Development, Xenon, Xeris, Zogenix, and Zynerba. J. French has also received research grants from Biogen, Cavion, Engage, Neurelis, Ovid, SK Life Science, Inc, UCB, and Zogenix, as well as grants from the Epilepsy Research Foundation, Epilepsy Study Consortium, and National Institute of Neurological Disorders and Stroke. She is on the editorial board of Lancet Neurology and Neurology Today. She is scientific officer for the Epilepsy Foundation, for which NYU receives salary support. She has received travel reimbursement related to research, advisory meetings, or presentation of results at scientific meetings from the Epilepsy Study Consortium, the Epilepsy Foundation, Adamas, Axovant, Biogen, Blackfynn, CuroNZ, Eisai, Engage, Idorsia, Neurelis, Novartis, Otsuka, Ovid, Pfizer, Redpin, Sage, SK Life Science, Inc, Sunovion, Takeda, UCB, Ultragenyx, and Zynerba. J. Kowalski has received research support from SK Life Science, Inc. G.L. Krauss is a consultant/advisor for Eisai, Otsuka, and Shire and received research support from SK Life Science, Inc, UCB, and Biogen. S.K. Lee is a consultant/advisor for Eisai, UCB, and SK Life Science, Inc. M. Maciejowski has served as a speaker for Biogen, Merck, Novartis, and Roche and received grant support from Roche. W.E. Rosenfeld is a consultant/advisor for SK Life Science, Inc and Eisai; has received honoraria for speaking from Eisai, Greenwich Biosciences (GW Pharmaceuticals), Sunovion, and UCB; and received grant/ research support from Greenwich Biosciences, Marinus, Medtronic, Neurelis, Ovid, SK Life Science, Inc, Takeda, UCB, and Upsher-Smith. M.R. Sperling is a consultant/advisor for Medtronic (fee to institution) and consultant to NeurologyLive and received research support (to institution) from Eisai, Engage, Medtronic, Neurelis, Pfizer, SK Life Science, Inc, Takeda, UCB, 
and Xenon. S. Mizne is an employee of MedVal Scientific Information Services, which was contracted by SK Life Science, Inc for medical writing services. M. Kamin is an employee of SK Life Science, Inc. Go to Neurology.org/N for full disclosures.

\section{Publication history}

Received by Neurology May 15, 2019. Accepted in final form November 25, 2019.

\section{Appendix Authors}

\begin{tabular}{lll}
\hline Name & Location & Contribution \\
\hline $\begin{array}{l}\text { Steve S. } \\
\text { Chung, MD }\end{array}$ & $\begin{array}{l}\text { Banner-University } \\
\text { Medical Center, University } \\
\text { of Arizona, Phoenix }\end{array}$ & $\begin{array}{l}\text { Major role in acquisition of } \\
\text { data; interpreted the data; } \\
\text { helped develop manuscript } \\
\text { and revised manuscript for } \\
\text { intellectual content }\end{array}$
\end{tabular}

\begin{tabular}{ll}
\hline Jacqueline A. & NYU Comprehensive \\
French, MD & Epilepsy Center, New York
\end{tabular}

Major role in acquisition of data; interpreted the data; helped develop manuscript and revised manuscript for intellectual content

\begin{tabular}{ll}
\hline Jacek & NZOZ Vito-Med, Gliwice, \\
Kowalski, MD & Poland
\end{tabular}

Designed and conceptualized study; analyzed and interpreted the data; helped develop manuscript and revised manuscript for intellectual content

$\begin{array}{ll}\text { Gregory L. } & \text { Johns Hopkins University } \\ \text { Krauss, MD } & \text { School of Medicine, } \\ & \text { Baltimore, MD }\end{array}$

Major role in acquisition of data; interpreted the data; helped develop manuscript and revised manuscript for intellectual content

\begin{tabular}{ll}
\hline Sang Kun & Adult Comprehensive \\
Lee, MD & Epilepsy Center, Seoul \\
& National University \\
& Hospital, Republic of \\
& Korea
\end{tabular}

Major role in acquisition of data; interpreted the data; helped develop manuscript and revised manuscript for intellectual content

\begin{tabular}{ll}
\hline Maciej & NZOZ Diagnomed Clinical \\
Maciejowski, & Research, Katowice, \\
MD, PhD & Poland
\end{tabular}

Major role in acquisition of data; interpreted the data; helped develop manuscript and revised manuscript for intellectual content

\begin{tabular}{ll}
\hline William E. & Comprehensive Epilepsy \\
Rosenfeld, & Care Center for Children \\
MD & and Adults, St. Louis, MO
\end{tabular}

Major role in acquisition of data; interpreted the data; helped develop manuscript and revised manuscript for intellectua content

\begin{tabular}{ll}
\hline Michael R. & Thomas Jefferson \\
Sperling, MD & University, Philadelphia, \\
& PA
\end{tabular}

Major role in acquisition of data; interpreted the data; helped develop manuscript and revised manuscript for intellectual content

\begin{tabular}{lll}
\hline $\begin{array}{l}\text { Sarah Mizne, } \\
\text { PharmD }\end{array}$ & MedVal Scientific & Wrote initial manuscript \\
Information Services, & draft based on input from \\
Princeton, NJ & the other authors and \\
revised the manuscript for \\
intellectual content under \\
their guidance; drafted and \\
revised the response to \\
reviewers with the guidance \\
of the other authors
\end{tabular}

\section{Appendix (continued)}

\begin{tabular}{lll}
\hline Name & Location & Contribution \\
\hline Marc Kamin, & SK Life Science, Inc, & Designed and \\
MD & Paramus, NJ & anceptualized study; \\
& & the data; helped develop \\
& manuscript and revised \\
& manuscript for intellectual \\
& content \\
\hline
\end{tabular}

\section{References}

1. Chen Z, Brodie MJ, Liew D, Kwan P. Treatment outcomes in patients with newly diagnosed epilepsy treated with established and new antiepileptic drugs: a 30-year longitudinal cohort study. JAMA Neurol 2018;75:279-286.

2. Brodie MJ, Barry SJ, Bamagous GA, Norrie JD, Kwan P. Patterns of treatment response in newly diagnosed epilepsy. Neurology 2012;78:1548-1554.

3. Kwan P, Brodie MJ. Early identification of refractory epilepsy. N Engl J Med 2000; 342:314-319.

4. Tian N, Boring M, Kobau R, Zack MM, Croft JB. Active epilepsy and seizure control in adults-United States, 2013 and 2015. MMWR Morb Mortal Wkly Rep 2018;67: 437-442.

5. Bialer M, Johannessen SI, Levy RH, Perucca E, Tomson T, White HS. Progress report on new antiepileptic drugs: a summary of the Eleventh Eilat Conference (EILAT XI). Epilepsy Res 2013;103:2-30.

6. Nakamura M, Cho JH, Shin HS, Jang IS. Effects of cenobamate (YKP3089), a newly developed anti-epileptic drug, on voltage-gated sodium channels in rat hippocampal CA3 neurons. Eur J Pharmacol 2019;855:175-182.

7. Sharma R, Song WS, Nakamura M, et al. Effects of cenobamate on GABA-A receptor modulation. Presented at American Epilepsy Society Annual Meeting; November 30-December 4, 2018; New Orleans, LA. Abstract 3.306.

8. Kasteleijn-Nolst Trenité D, DiVentura BD, Pollard JR, Krauss GL, Mizne S, French JA. Suppression of the photoparoxysmal response in photosensitive epilepsy with cenobamate (YKP3089). Neurology 2019;93:e559-e567.

9. Scheffer IE, Berkovic S, Capovilla G, et al. ILAE classification of the epilepsies: position paper of the ILAE Commission for Classification and Terminology. Epilepsia 2017;58:512-521.

10. Fisher RS, Cross JH, French JA, et al. Operational classification of seizure types by the International League Against Epilepsy: position paper of the ILAE Commission for Classification and Terminology. Epilepsia 2017;58:522-530.

11. Vernillet L, Kamin M. Drug-drug interactions between cenobamate and other antiepileptic drugs: results from phase I studies with carbamazepine, phenobarbital, phenytoin, and divalproex sodium. Clin Pharmacol Ther 2018;103(suppl S1):S91. Abstract.

12. Greene S, Kwak C, Kamin M, Vernillet $L$. The effect of cenobamate on the single dose pharmacokinetics of multiple cytochrome $\mathrm{P} 450$ probes using a cocktail approach in healthy subjects. Clin Pharmacol Ther 2019;105(suppl 1):S97. Abstract.

13. Gil-Nagel A, Zaccara G, Baldinetti F, Leon T. Add-on treatment with pregabalin for partial seizures with or without generalisation: pooled data analysis of four randomised placebo-controlled trials. Seizure 2009;18:184-192.

14. Peeters K, Adriaenssen I, Wapenaar R, Neto W, Pledger G. A pooled analysis of adjunctive topiramate in refractory partial epilepsy. Acta Neurol Scand 2003;108: 9-15.

15. Steinhoff BJ, Ben-Menachem E, Ryvlin P, et al. Efficacy and safety of adjunctive perampanel for the treatment of refractory partial seizures: a pooled analysis of three phase III studies. Epilepsia 2013;54:1481-1489.

16. Ben-Menachem E, Mameniskiene R, Quarato PP, et al. Efficacy and safety of brivaracetam for partial-onset seizures in 3 pooled clinical studies. Neurology 2016;87: 314-323.

17. Costa J, Fareleira F, Ascencao R, Borges M, Sampaio C, Vaz-Carneiro A. Clinical comparability of the new antiepileptic drugs in refractory partial epilepsy: a systematic review and meta-analysis. Epilepsia 2011;52:1280-1291.

18. Krauss GL, Serratosa JM, Villanueva V, et al. Randomized phase III study 306: adjunctive perampanel for refractory partial-onset seizures. Neurology 2012;78: $1408-1415$

19. French JA, Krauss GL, Biton V, et al. Adjunctive perampanel for refractory partialonset seizures: randomized phase III study 304. Neurology 2012;79:589-596.

20. French JA, Krauss GL, Steinhoff BJ, et al. Evaluation of adjunctive perampanel in patients with refractory partial-onset seizures: results of randomized global phase III study 305. Epilepsia 2013;54:117-125.

21. Ryvlin P, Werhahn KJ, Blaszczyk B, Johnson ME, Lu S. Adjunctive brivaracetam in adults with uncontrolled focal epilepsy: results from a double-blind, randomized, placebo-controlled trial. Epilepsia 2014;55:47-56.

22. Biton V, Berkovic SF, Abou-Khalil B, Sperling MR, Johnson ME, Lu S. Brivaracetam as adjunctive treatment for uncontrolled partial epilepsy in adults: a phase III randomized, double-blind, placebo-controlled trial. Epilepsia 2014;55:57-66.

23. Klein P, Schiemann J, Sperling MR, et al. A randomized, double-blind, placebocontrolled, multicenter, parallel-group study to evaluate the efficacy and safety of 
adjunctive brivaracetam in adult patients with uncontrolled partial-onset seizures. Epilepsia 2015;56:1890-1898.

24. Biton V, Rogin JB, Krauss G, et al. Adjunctive eslicarbazepine acetate: a pooled analysis of three phase III trials. Epilepsy Behav 2017;72:127-134.

25. Chung SS, Fakhoury TA, Hogan RE, et al. Once-daily USL255 as adjunctive treatment of partial-onset seizures: randomized phase III study. Epilepsia 2014;55: 1077-1087.

26. French JA, Baroldi P, Brittain ST, Johnson JK. Efficacy and safety of extended-release oxcarbazepine (Oxtellar $\mathrm{XR}^{\mathrm{TM}}$ ) as adjunctive therapy in patients with refractory partial-onset seizures: a randomized controlled trial. Acta Neurol Scand 2014;129: $143-153$.

27. Sperling MR, Abou-Khalil B, Harvey J, et al. Eslicarbazepine acetate as adjunctive therapy in patients with uncontrolled partial-onset seizures: results of a phase III, double-blind, randomized, placebo-controlled trial. Epilepsia 2015;56:244-253.

28. Chung S, Ben-Menachem E, Sperling MR, et al. Examining the clinical utility of lacosamide: pooled analyses of three phase II/III clinical trials. CNS Drugs 2010;24: 1041-1054.

29. Hesdorffer DC, Tomson T, Benn E, et al. Combined analysis of risk factors for SUDEP. Epilepsia 2011;52:1150-1159.

30. French JA, Abou-Khalil BW, Leroy RF, et al. Randomized, double-blind, placebocontrolled trial of ezogabine (retigabine) in partial epilepsy. Neurology 2011;76: $1555-1563$.
31. Chung S, Sperling MR, Biton V, et al. Lacosamide as adjunctive therapy for partialonset seizures: a randomized controlled trial. Epilepsia 2010;51:958-967.

32. Josephson CB, Patten SB, Bulloch A, et al. The impact of seizures on epilepsy outcomes: a national, community-based survey. Epilepsia 2017;58:764-771.

33. Leppik I, De Rue K, Edrich P, Perucca E. Measurement of seizure freedom in adjunctive therapy studies in refractory partial epilepsy: the levetiracetam experience. Epileptic Disord 2006;8:118-130.

34. Gazzola DM, Balcer LJ, French JA. Seizure-free outcome in randomized add-on trials of the new antiepileptic drugs. Epilepsia 2007;48:1303-1307.

35. Carpay JA, Aldenkamp AP, van Donselaar CA. Complaints associated with the use of antiepileptic drugs: results from a community-based study. Seizure 2005;14 198-206.

36. Zaccara G, Franciotta D, Perucca E. Idiosyncratic adverse reactions to antiepileptic drugs. Epilepsia 2007;48:1223-1244.

37. Borrelli EP, Lee EY, Descoteaux AM, Kogut SJ, Caffrey AR. Stevens-Johnson syndrome and toxic epidermal necrolysis with antiepileptic drugs: an analysis of the US Food and Drug Administration Adverse Event Reporting System. Epilepsia 2018;59: 2318-2324.

38. Sperling M, Klein P, Kamin M. Safety of cenobamate (YKP3089) as adjunctive treatment for uncontrolled partial seizures in a large, multicenter, open-label study [abstract]. Presented at American Epilepsy Society Annual Meeting; November 30-December 4, 2018; New Orleans, LA. Abstract 1.303. 


\section{Neurology}

\section{Randomized phase 2 study of adjunctive cenobamate in patients with uncontrolled focal seizures \\ Steve S. Chung, Jacqueline A. French, Jacek Kowalski, et al.}

Neurology 2020;94;e2311-e2322 Published Online before print May 14, 2020

DOI 10.1212/WNL.0000000000009530

\section{This information is current as of May 14, 2020}

\section{Updated Information \& Services}

References

Citations

Subspecialty Collections

Permissions \& Licensing

Reprints including high resolution figures, can be found at: http://n.neurology.org/content/94/22/e2311.full

This article cites 36 articles, 6 of which you can access for free at: http://n.neurology.org/content/94/22/e2311.full\#ref-list-1

This article has been cited by 1 HighWire-hosted articles: http://n.neurology.org/content/94/22/e2311.full\#\#otherarticles

This article, along with others on similar topics, appears in the following collection(s):

\section{Antiepileptic drugs}

http://n.neurology.org/cgi/collection/antiepileptic_drugs

\section{Class I}

http://n.neurology.org/cgi/collection/class_1

Clinical trials Randomized controlled (C)

http://n.neurology.org/cgi/collection/clinical_trials_randomized_contro

lled_consort_agreement

Partial seizures

http://n.neurology.org/cgi/collection/partial_seizures

Information about reproducing this article in parts (figures,tables) or in its entirety can be found online at:

http://www.neurology.org/about/about_the_journal\#permissions

Information about ordering reprints can be found online:

http://n.neurology.org/subscribers/advertise

Neurology ${ }^{\circledR}$ is the official journal of the American Academy of Neurology. Published continuously since 1951, it is now a weekly with 48 issues per year. Copyright Copyright ( 2020 The Author(s). Published by Wolters Kluwer Health, Inc. on behalf of the American Academy of Neurology.. All rights reserved. Print ISSN: 0028-3878. Online ISSN: 1526-632X.

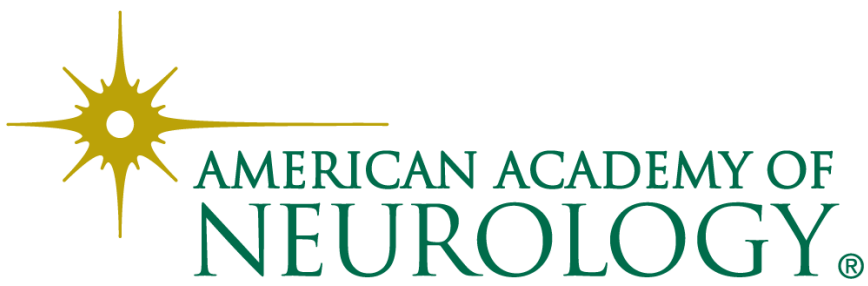

